\section{ECONOMICS OF DRIP METHOD OF IRRIGATION IN RED CHILLI CROP CULTIVATION: AN EMPIRICAL STUDY FROM TAMIL NADU}

\author{
N. Devika \\ A. Narayanamoorthy \\ and \\ P. Jothi*
}

\begin{abstract}
Considering the fast decline of irrigation potential and increased demand for water from different sectors, many initiatives have been introduced to conserve the scarce water resources in India. One of the methods introduced to save water consumption in agriculture was drip method of irrigation (DMI). It allows the farmers to cultivate the crops without moisture stress even under water scarcity conditions and therefore, DMI is also considered as an useful method for increasing the productivity of crops. Most of the earlier studies have analysed the economics of DMI by taking high value crops such as banana, sugarcane, grapes, etc., which are mostly cultivated by the resourceful farmers. DMI is also highly suitable for vegetable crops, such as red chilli, that are mostly cultivated by small landholders. However, detailed studies are seldom available on this crop using farm level data especially in the Indian context. An attempt is made in this study to fill this gap using farm level data collected from Sivagangai district of Tamil Nadu State. This study shows that farmers can save about 43 per cent of water and increase productivity of red chilli by 39 per cent by adopting drip method of irrigation over the same crop cultivated under conventional flood method of irrigation. The profitability of chilli cultivating farmers under drip method of irrigation is about 205 per cent more than the non-drip adopters. Both NPV and $B C R$, estimated using the discounted cash flow analysis, show that the drip investment in red chilli cultivation is economically viable even without State's subsidy.
\end{abstract}

\footnotetext{
*Research Scholar, Professor and Head and Research Scholar, Respectively, Department of Economics and Rural Development, Alagappa University, Karaikudi- 630 003, Tamil Nadu.

The paper is generated through the study on "Micro-irrigation and Social Safety Net Nexus in SemiArid Tropics of India" funded by CGIAR through CRP2 and implemented by ICRISAT, Hyderabad.
} 


\section{Introduction}

Irrigation water is a critical input for agriculture. Therefore, it is often considered as an engine of agricultural growth. Many research studies have underlined that irrigation water plays a critical role for sustained reduction of rural poverty. But, the state of water scenario is very precarious in India today. ${ }^{1}$ While the available potential of water for future use has been declining at a faster rate, the demand for water has been increasing at an alarming rate due to its ever increasing demand for the energy, industry and domestic purposes in India (MoWR, 1999; CWC, 2010; $\mathrm{FICCl}, 2013$ ). Despite this, the irrigation water in India is predominantly applied through the conventional flood method of irrigation where the efficiency of water is very low ranging from 35-40 per cent because of huge conveyance and distribution losses (INCID, 1994; Postal, et al., 2001; Gol, 2004, Narayanamoorthy, 2005). The low irrigation water use efficiency substantially reduces the anticipated outcomes from investments in the water resources sector of the country.

To improve the efficiency of existing irrigation water use as well as to reduce the water stress in agricultural sector, various initiatives have been undertaken in India in recent years. Drip method of irrigation (DMI) has received substantial attention by Central and State governments. In this method, water is supplied straight to crop root zone through a well-structured pipe network, where the efficiency of water use is extremely high as it substantially reduces the evaporation, conveyance and distribution losses of water (Dhawan, 2002). Besides, drip method of irrigation helps to reduce the cost of cultivation in many operations of crop cultivation (Narayanamoorthy, 1997 \& 2010; MoWR, 2006).

Many studies conducted with the use of experimental and field survey data across different regions of India have shown that the water saving and water use efficiency of various crops cultivated under drip method of irrigation is significantly higher as compared to flood method of irrigation (Narayanamoorthy, 2004a, 2005 \& 2009; Dhawan, 2002). Moisture stress is completely absent under DMI and thus, the productivity of crops is found to be significantly higher than those crops cultivated under flood method of irrigation (Shah and Keller, 2014). The return from crops is also found to be substantially higher under DMI mainly due to increased productivity and reduced cost of cultivation. However, most studies on drip method of irrigation have considered only the wide-spaced fruit and vegetable crops while studying its various economic benefits including profitability. Drip irrigation is not only suitable for wide-spaced crops but it is also highly suitable for many narrow-spaced crops including chilli, which is mainly cultivated by the small landholders. In fact, the INCID (1994) underlined that over 85 crops are suitable for cultivation under DMI. Importantly, in the recent time, a large number of farmers started cultivating chilli crop by adopting drip method of irrigation. What could be the main reason for it? Could this be due to increased water scarcity or any 
other reasons? Since studies seldom are available on the economics of drip method of irrigation especially on short duration crops like chilli particularly in Tamil Nadu which is a very water scarce State in India ${ }^{2}$, an attempt has been made in this study to fill this gap. The major objectives of the study are as follows:

1. To study the operation-wise cost of cultivation of drip and non-drip irrigated red chilli crop;

2. To estimate the water and electricity saved due to drip method of irrigation in red chilli crop;

3. To study the impact of adoption of drip method of irrigation on productivity and profitability of red chilli crop;

4. To find out the economic viability of drip investment in red chilli crop cultivation with the help of discounted cash flow technique.

\section{Empirical Setting}

Farm level survey data collected from Sivagangai district of Tamil Nadu have been used for the entire analysis of the study. Tamil Nadu has been one of the leading States in agricultural production from the very beginning of planning period. Despite fast urban agglomeration, about 44 per cent of the population is still engaged in agriculture and allied activities for livelihood in the State. With the gross cropped area of about 5.14 million hectares (mha), Tamil Nadu accounted for about 2.65 per cent of India's total cropped area in 2012-13 (Gol, 2014). Although the production and productivity of foodgrain and other crops have been very impressive in Tamil Nadu as compared to most States in India over the years, there has been a deceleration in agricultural growth especially in recent years mainly because of water scarcity (GoTN, 2013).

In the context of limited availability of irrigation water, over-exploitation phenomenon and stagnant growth in irrigated area, there is an urgent need to increase the efficiency in the existing use of irrigation water in the State. Keeping this in view, the State government has been making efforts to popularise the water saving methods like drip and sprinkler methods of irrigation by providing handsome subsidy for farmers (GoTN, 2014). ${ }^{3}$ Because of State's initiatives not only the adoption of drip irrigation in different crops expanded but it also led to significant advantages especially in water use efficiency and productivity in certain crops in the State (Narayanamoorthy, 2005a). Therefore, from the point of view of water scarcity and efficiency angle of water use, Tamil Nadu appears to be suitable choice to empirically evaluate the impact of drip irrigation on red chilli cultivation.

The field survey data for this study was collected from Sivagangai district where drip irrigation was extensively used for cultivating red chilli crop, which was also fairly evident from the secondary data published by the 
Government of Tamil Nadu. Among the various blocks in the district, llanyangudi block was selected for a detailed study because of widespread cultivation of red chilli crop using DMI as well as conventional flood method of irrigation (FMI). A total of 60 farmers, consisting of 30 drip adopters and 30 non-drip adopters, were selected for a detailed field survey data. As the adoption of drip method of irrigation was found only among the farmers who owned irrigation wells (groundwater), farmers who cultivated red chilli using groundwater source of irrigation under both drip and flood irrigated conditions had been selected for this study. While the adopters were selected using random sampling procedure with the help of adopters' list provided by the Agricultural Officer of the block, purposive sampling method was followed to select the non-drip irrigated farmers who cultivated the same crop nearest to the field of drip adopters. The relevant data on the economics of DMI were collected during the year 2013-14 that formed the basis for the field level evaluation of DMI.

A major objective of the study is to find out the economic viability of investment in drip irrigation in red chilli cultivation. For this purpose, net present worth (NPW) and benefit-cost ratio (BCR) have been estimated using discounted cash flow technique (Gittinger, 1984). The NPW and BCR can be mathematically defined as follows:

$$
\mathrm{NPW}=\sum_{t=1}^{t=n} \frac{B_{t}-C_{t}}{(1+i)^{t}}
$$

$$
\mathrm{BCR}=\frac{\sum_{i=1}^{k-n} \frac{B_{i}}{(1+i) !}}{\sum_{i=1}^{n-1} \frac{C_{i}}{(1+i) !}}
$$

[Where, $\mathrm{Bt}=$ benefit in year $\mathrm{t}$; $\mathrm{Ct}=$ cost in year $t ; t=1,2,3, \ldots \ldots . n ; n=$ project life in years; $i=$ rate of interest or the assumed opportunity cost of the investment]

Fixed capital is required for adopting drip irrigation in any crop and therefore, it is necessary to take into account the income and cost stream for the whole life span of drip investment. But it is difficult to collect the actual cash flows for the entire life span of drip investment because of the absence of observed temporal information on benefits and costs. Therefore, the following realistic assumptions are used to estimate the cash inflows and outflows for drip investment:

1. The life period of the drip-set is assumed as five years for red chilli as followed by the INCID (1994) study.

2. The cost of cultivation incurred and income generated through red chilli cultivation using drip method of irrigation is assumed constant during the entire life period of drip-set.

3. Different rates of discount (interest rates) are considered to study the sensitivity of investment to the change in capital cost. They are assumed at 10, 12 and 15 per cent as alternatives representing different opportunity costs of capital. 
4. The cultivation technology of red chilli crop is assumed to remain constant during the entire life period of drip-set.

\section{Analysis of Data}

As mentioned earlier, although drip method of irrigation is primarily introduced to conserve the water consumption in crop cultivation, studies have shown that DMI's impact is also very significant in increasing the productivity and profitability of crops, reducing electricity consumption and cost of cultivation of different crops. Economic viability of drip investment is also found to be viable in different crops even without the capital subsidy provided by the Central and State governments. We will now study how far this is true in red chilli crop cultivation?

Cost of Cultivation: It is evident from different studies carried out with the help of field level data that DMI reduces the cost of cultivation, especially in labour-intensive operations like weeding, irrigation, ploughing, etc., (Narayanamoorthy 1996 \& 1997). When labour cost reduces, the total cost of cultivation also reduces because labour cost constitutes a considerable portion in the total cost of cultivation. In order to understand the impact of drip irrigation on cost of cultivation of different operations, we have compared the operation-wise cost of drip and non-drip irrigated red chilli crop. ${ }^{4}$ Table 1 shows that the farmers cultivating chilli are able to save about 38 per cent of cultivation cost per acre as compared to their counterparts (non-drip adopters). Among the various operations, substantial amount of cost saving is noticed in operations like irrigation ${ }^{5}$ (about 78 per cent), weeding and interculture (about 52 per cent) and fertilisers (about 38 per cent). These are not surprising results. Since water is supplied at the root zone of the crop instead of the entire land, the total consumption of water is substantially reduced under DMI as compared to the conventional flood method of irrigation. The reduced consumption of water under DMI leads to substantial reduction in the cost on irrigation. Under this new method, as water is supplied only at the root of the crops and not to the non-crop zone, weed growth is reduced substantially. As a result of reduced weed growth, the requirement of labour for weeding and interculture operations in red chilli cultivation is substantially reduced. ${ }^{6}$ Substantial reduction in fertiliser consumption under drip irrigated chilli happened because of use of liquid fertilisers which help to avoid lot of wastages. It is clear from above that DMI has the capability of reducing considerable amount of cost of cultivation in chilli crop over the method of flood irrigation. 
N.Devika,A.Narayanamoorthy and P.Jothi

Table 1: Cost of Cultivation of Red Chilli for DMI Adopters and Non-adopters

\begin{tabular}{|lccc|}
\multicolumn{1}{l}{ (₹/Acre) } \\
\hline 1. Preparatory works & DMI & FMI & \% Change over FMI \\
2. Seed \& sowing & 4358.33 & 5350.00 & -18.54 \\
3. Fertilisers (in-organic) & $(658.38)$ & $(804.51)$ & \\
& 1626.67 & 1935.00 & -15.93 \\
4. Farmyard manure & $(668.47)$ & $(262.33)$ & -37.55 \\
& 2887.67 & 4624.17 & \\
5. Pesticides & $(514.24)$ & $(718.10)$ & 6.43 \\
6. Weeding \& interculture & 1241.67 & 1166.67 & -8.58 \\
& $(401.52)$ & $(163.75)$ & -52.22 \\
7. Irrigation & 774.00 & 846.67 & \\
& $(32.86)$ & $(63.64)$ & -77.99 \\
8. Harvesting plus marketing & 4399.00 & 9206.67 & \\
Total cost of cultivation & $(936.22)$ & $(2431.03)$ & 66.50 \\
& 3753.33 & 17053.33 & \\
\hline
\end{tabular}

Note: Figures in parentheses are standard deviation.

Water and Electricity Consumption:The major advantage of drip method of irrigation is water saving. As water is supplied directly to the root zone of the crop through DMI, considerable amount of water losses occurring due to conveyance, distribution and application are reduced at the field level. Under experimental based studies, water consumption is generally estimated as depth of water applied in terms of centimetre $(\mathrm{cm})$ or millimetre $(\mathrm{mm})$. But, it is difficult to follow the same method at the farmers' field due to changes in the horse power (HP) of the pumpset, water level in the well, varying level of delivery pipes, different size of water extraction machineries, distance between place of water source and field to be irrigated, soil quality, terrain condition, etc. Therefore, water consumption is measured in terms of horse power (HP) hours of irrigation. HP hours of water consumption is computed by multiplying pumpset HP with hours of water used by farmers with drip and without drip.

Data presented in Table 2 show that water saving is substantial due to the use of drip method of irrigation in red chilli cultivation. Although the number of irrigations used for drip irrigated crop (about 120 times) is substantially higher than that of flood irrigated 
crop (48 times), the duration of hours used for each turn of irrigation is only about 1.73 hours under DMI as against the use of 7.40 hours per acre under FMI. As a result, the total water used for drip-irrigated red chilli comes to about $1052.53 \mathrm{HP}$ hours/acre, but the same comes to about 1834.70 HP hours for non-drip irrigated red chilli crop. This means that drip farmers are able to save about 782.17 HP hours of water per acre, which is a saving of about 43 per cent over FMI. As farmers are able to supply required quantity of water at the required time exclusively at the root zone of the crop under DMI, a substantial water saving is achieved. But, the same area farmers are unable to achieve this when red chilli is cultivated under flood method of irrigation. Although the water used under FMI is much higher under DMI, farmers practising FMI reported that they were not able to provide adequate quantity of water during the time of crop growth mainly due to water shortage in the well and also due to frequent interruptions in electricity supply. Therefore, red chilli crop cultivators had faced either moisture stress or excess wetting during the crop season, which significantly impacted the crop growth. Farmers reported that interruptions in electricity supply and water scarcity were the important reasons for adopting the drip method of irrigation for red chilli cultivation.

Table 2 : Water and Electricity Consumption in Drip and Flood Irrigated Red Chilli

\begin{tabular}{|lcccc|}
\hline Particulars & DMI & FMI & \multicolumn{2}{c|}{ Gain over FMI } \\
\hline Pumpset HP & & & Quantity & Per cent \\
Number of irrigations/acre & 5.07 & 5.13 & --- & --- \\
Hours required per irrigation/acre & 120.00 & 48.33 & -71.67 & -148.29 \\
HP hours of water used/acre & 1.73 & 7.40 & 5.67 & 76.62 \\
Electricity consumption (kWh/acre) & 1052.53 & 1834.70 & 782.17 & 42.63 \\
\end{tabular}

Another important advantage of drip method of irrigation is saving of electrical energy used for operating irrigation pumpsets, which is not adequately highlighted by the existing studies while analysing the economics of drip method of irrigation. With the reduction of consumption of water, drip irrigated crop substantially curtails the working hours of pumpset leading to reduction in the required quantum of electricity. In this study, we have estimated electricity saving by assuming that $0.750 \mathrm{kWh}$ of power is used per HP for every hour of pumpset operation which is also followed by some earlier studies (Shah, 1993). As per this estimate, the consumption of electricity under DMI is only about $789 \mathrm{kWh}$ / acre as against 1376 kWh / acre under FMI. This means that the drip adopters are able to save about $587 \mathrm{kWh}$ of electricity from every acre of red chilli cultivation over the method of flood irrigation. It is appropriate to mention here that the amount of electricity saving achieved because of adoption of DMI would go up significantly when farmers adopt this 
same technology in water-intensive annual crops such as sugarcane and other similar crops.

Productivity Augmentation: Along with substantial water saving, drip method of irrigation helps in increasing the productivity of crops to a considerable extent by completely reducing the moisture stress. Table 3 clearly illustrates that the productivity of red chilli cultivated under DMI (18.17 quintal / acre) is about 39 per cent higher than that under FMI, which is only 13.03 quintal / acre. There are many reasons for substantial increase in productivity under DMI. First, the moisture stress for crop under DMI is avoided because of its ability to supply required quantity of water at the required time. This has increased the plant growth increasing the number of canopies from which more flowers and red chilli have been produced. Second, supply of water only at the root zone of the crop prevents water flow to other zones of the land and thus, weed growth is considerably reduced. Third, the supply of water at regular intervals also allowed the crop to absorb the fertilisers without any big losses through leaching and evaporation. Fourth, pre-mature dropping of baby chilli is reported to be less under drip method because of the absence of moisture stress. Fifth, the better growth of plant under DMI allows for extendable harvest of red chilli which is not possible under FMI. Apart from increasing productivity of crops in absolute terms, DMI also helps enhancing the water and electricity productivity of chilli crop (see, row three and four in Table 3). This is also an important advantage of DMI in view of increased scarcity of water and electricity experienced by the farmers in recent years.

Table 3: Productivity of Drip and Flood Irrigated Red Chilli

\begin{tabular}{|lcccc|}
\hline Particulars & DMI & FMI & \multicolumn{2}{c|}{ Gain over FMI } \\
\hline & & & Amount & Per cent \\
\hline 1. Productivity (quintal/acre) & 18.17 & 13.03 & 5.13 & 39.39 \\
2. Cost of production (₹/quintal) & 1573.89 & 3523.21 & -1949.32 & -55.33 \\
3. Water productivity (kg/HP hours of water) & 1.73 & 0.71 & 1.02 & 143.08 \\
4. Electricity productivity (kg/kWh) & 2.30 & 0.95 & 1.35 & 143.08 \\
\hline
\end{tabular}

\section{Un-discounted Profit from Red Chilli under DMI}

Water saving and productivity gains from red chilli alone cannot guarantee the farmers to adopt this irrigation method unless it is profitable to them. Given this, it is important to understand the relative profitability of red chilli cultivated under drip and flood irrigated methods. It is to be noted here that the total cost of cultivation considered for calculating the profitability of red chilli crop is calculated taking into consideration only the variable cost, but not fixed cost components such as interest rate and depreciation. The gross income from red chilli is calculated by multiplying total yield with the price received (varied from ₹ 60 to $₹ 70$ per $\mathrm{kg}$ ) from the market by the farmers. To calculate the 
profitability in chilli cultivation, the total cost of cultivation is subtracted from the gross value of production under DMI and FMI. As per this method, the profit per acre estimated comes to ₹ 98574 for DMI, but it is only ₹ 32281 for FMI (Table 4)7. This means that farmers cultivating red chilli under the method of drip irrigation are able to generate an additional profit of ₹ 66294/acre over the method of conventional flood irrigation. We have also analysed as to how are the farmers cultivating chilli under DMI making substantial profit? Is this due to the effect of productivity or due to the effect of price? Farmers selected for this study cultivated more or less uniform variety of red chilli and therefore, they had received almost the same price for their crop harvested from drip and flood irrigated fields. With this one may conclude that this higher profit is purely because of yield effect under DMI and not due to any price effect. One interesting point that surfaces from this profitability analysis is that the farmers can also repay the whole capital cost of the drip system utilising the profit from the very first year itself.

\section{Economic Viability of Drip Investment in Red} Chilli:Adoption of drip method of irrigation in the field involves certain amount of fixed investment, which varies from crop to crop. One must study whether the investment is economically viable to the farmers cultivating chilli who are mostly marginal and small holders having land size less than 2.00 hectares. It is noted in the preceding section that the profit (farm business income) from red chilli cultivation with drip method of irrigation is significantly higher than the profit under conventional irrigation method. However, this profit cannot be treated as the effective (real) profit of red chilli cultivated under DMI. This is because of the fact that it does not take into account the capital cost of the drip-set, its depreciation and the interest accrued on using the fixed capital for installing the drip-set in the field. In order to calculate the net profit in a prudent method, all these parameters should be taken into account. Importantly, the life period of the drip-set is an important factor that determines the net present value, which in turn is a determinant of per hectare profit.

Table 4: Relative Profit Levels of Drip and Flood Irrigated Red Chilli

\begin{tabular}{|lcccc|}
\hline Particulars & DMI & FMI & \multicolumn{2}{c|}{ Gain over FMI } \\
\hline & & & Amount & Per cent \\
\hline 1. Gross cost of cultivation & 28592.34 & 45919.18 & 17326.84 & 37.73 \\
2. Gross value of production & 127166.67 & 78200.00 & 48966.67 & 62.62 \\
3. Profit (farm business income) & 98574.33 & 32280.82 & 66293.51 & 205.37 \\
4. Capital cost of DMI (without subsidy) & 32000.00 & --- & --- & --- \\
5. Subsidy for DMI & 16000.00 & --- & --- & --- \\
6. Capital cost of DMI (with subsidy) & 16000.00 & --- & --- & --- \\
\hline
\end{tabular}

Note: Cost of cultivation used in this study refers to cost $A 2+F L$. 
DMI is also a capital-intensive technique and therefore, the initial high investment needed for installing drip system remains the main hindrance for the widespread adoption of it, especially in crops like red chilli which is not water-intensive. How is the requirement of fixed investment affecting the economic viability of red chilli cultivation under DMI? To what extent the lumpiness of investment can be counterbalanced by government subsidy are some of the central policy issues. In view of these reasons, there is a need to find out the economic viability of drip investment in red chilli cultivation under different scenarios. Generally to answer these issues, Net Present Worth (NPW) and the Benefit-Cost Ratio (BCR) are estimated by utilising the discounted cash flow technique, which is carried out in this study as well.

The fixed investment required is one of the critical factors that determines the economic viability of the drip irrigation in any crop. Therefore, it is useful to understand the requirement of investment for drip irrigation before getting into the economic viability of the system. The capital investment required for DMI varies depending upon the crop; narrow-spaced crops need higher fixed investment, whereas wide-spaced crops require relatively low fixed investment. The lesser requirement of tube length, emitters and drippers for wide-spaced crops allows for less investment. States including Tamil Nadu are mostly providing almost 50 per cent of the capital cost as subsidy either through a Statesponsored scheme or Centrally-sponsored scheme to encourage the adoption of drip irrigation for different crops considering its capital-intensive nature. In this study, the average capital cost required for installing drip system for red chilli crop comes to ₹ 32,000 I acre without subsidy, whereas it is only ₹ 16000 / acre after deducting the State subsidy (Table 4). That is, on an average, farmers installing drip system for chilli cultivation were able to realise the capital subsidy close to the tune of $₹ 16,000 /$ acre.

After understanding the capital requirements of drip system, we turned our analysis towards the benefit-cost pattern of drip investment estimated using discounted cash flow technique. The NPW and the BCR were computed separately by including and excluding subsidy in the total fixed capital cost of drip-set. Economic viability analysis under different rates of discount would indicate the efficacy of investment at various levels of the opportunity cost of investment. BCR is sensitive to discount rate, but the degree of such sensitivity depends on the pattern of cash flows generated during the entire life period of the drip system. Therefore, it is interesting to observe the sensitivity of $\mathrm{BCR}$ when there is simultaneous change in both subsidy and discount factor. Considering all these issues, we attempted to find out answers specifically to the following four important questions: (1) Is the investment in drip system for red chilli cultivation economically viable to farmers? (2) Will the farmers be able to meet the investment in drip irrigation to cultivate red chilli without subsidy on capital cost?

Journal of Rural Development, Vol. 36, No. 3, July-September : 2017 
(3) What is the payback period of drip investment? and (4) What will be the trend in the NPW and BCR when the assumed life period of the drip system is 5 years?

Both the NPW and BCR computed under different scenarios show that the drip investment in red chilli cultivation is economically viable for farmers (Table 5). NPW of investment with subsidy is marginally higher than that under 'no subsidy' option under all scenarios used for analysis which is on the expected line. For instance, NPW at 10 per cent discount rate computed assuming five years as life period of the system comes to $₹ 3,44,583$ /acre without subsidy and ₹ 3,59,129 / acre with subsidy. This means that the capital subsidy provided by the State government enables the farmers to get an additional benefit to the tune of about ₹ $14,546 /$ acre.

Table 5: NPW and BCR Estimated Using Actual Price Received by the Sample Farmers for Drip Irrigated Red Chilli

\begin{tabular}{|lcccc|}
\hline Subsidy Category & Life Period Assumed & $\begin{array}{c}\text { Discount Rate } \\
\text { (Percentage) }\end{array}$ & NPW (₹/Acre) & BCR \\
\hline With subsidy & 5 years & 15 & 316523.39 & 3.88 \\
& & 12 & 341052.67 & 3.91 \\
& & 10 & 359128.80 & 3.92 \\
Without subsidy & 5 years & 15 & 302610.34 & 3.45 \\
& & 12 & 326766.96 & 3.48 \\
& & 10 & 344583.34 & 3.51 \\
\hline
\end{tabular}

Notes: Computed using discounted cash flow technique for actual price; NPW- Net Present Worth; BCR - Benefit-Cost Ratio.

The estimated BCR under different discount rates clearly suggests that drip investment is economically viable for red chilli farmers under all scenarios, both with and without subsidy. The minimum BCR comes to 3.45 and the maximum goes up to 3.51 when one estimates the same without considering subsidy. When BCR is calculated after deducting the subsidy from the capital cost, it further increases from 3.88 to 3.92. The relatively higher BCR realised with subsidy indicates the important role played by the subsidy in augmenting the economic viability of drip irrigation in red chilli cultivation. The minimum BCR estimated at 3.45 without subsidy underlines the fact that the investment in drip irrigation in red chilli cultivation is economically viable for farmers even without availing State subsidy. This also means that farmers can realise at least ₹ 3.45 from every rupee of investment made in cultivating red chilli under drip method of irrigation.

\section{Conclusion and Recommendations}

Drip method of irrigation was introduced in India with the objectives of reducing the consumption of water and increasing the productivity of crops. Most of 
the earlier studies analysed the economics of drip method of irrigation by taking high value crops such as banana, sugarcane, grapes, etc., which are mostly cultivated by the rich resourceful farmers. Drip method of irrigation is also highly suitable for vegetable crops, which are mostly cultivated by small holders. However, detailed studies are seldom available on the economics of vegetable crop cultivation under drip method of irrigation using farm level data. An attempt has been made in this paper to study the economics of drip method of irrigation in red chilli cultivation. The study shows that cultivating red chilli under drip method of irrigation provides a number of benefits to farmers over FMI. Water saving due to adoption of drip method of irrigation in red chilli cultivation is estimated to be about 43 per cent over FMI. Through the reduction of working hours of pumpset that occurred due to water saving DMI helps reducing the consumption of electricity to the tune of about $587 \mathrm{kWh} /$ acre over the conventional irrigation method. The productivity difference between drip and flood irrigated red chilli comes to about 5 quintal/acre, which is about 39 per cent higher than the same harvested using flood method of irrigation.

Besides saving water and increasing productivity in absolute terms, DMI has also increased the water productivity and the electricity productivity substantially which are essential given the scarcity of water resources and electricity. The farm business income (undiscounted profit) of the red chilli crop cultivated using DMI is also substantially higher by about ₹66,294/ acre (about 205 per cent) than that of the profit realised from the same crop cultivated with conventional flood method of irrigation. The net present worth (NPW) and benefit-cost ratio (BCR) estimated using discounted cash flow technique show that the drip investment in red chilli cultivation is economically viable under all conditions; 'with' and 'without' subsidy as well as under different discount rates. The lowest BCR estimated at 15 per cent discount rate without capital subsidy itself comes to 3.45 , which is very high by any standard. The analysis also shows that the farmers would be able to repay the entire capital cost of drip system incurred for cultivating red chilli from the profit of the very first year itself.

The export of chilli has been rising over the last few years due to increased demand and short supply from other major producing countries like China and Pakistan. According to the report of vegetable statistics of 2013, the Indian exports of red chilli increased from 31,002 tonnes in 2008-09 to 46,909 tonnes in 2010-11 (Vanitha, et al., 2013). As there is growing demand for red chill, drip irrigation can be used as a tool to increase its productivity. The study suggests that cultivation of red chilli crop under drip method of irrigation would greatly benefit, especially the small farmers. Not only in Tamil Nadu but elsewhere in the country, farmers are unable to increase the productivity of red chilli due to inadequate water supply through conventional flood method of irrigation. In 
view of this, farmers are able to realise only a very low profit. Research studies (for example, Amarasinghe and Smakhtin, 2014) suggest that water availability for irrigation purpose is going to be reduced in the future owing to various reasons. This is expected to create serious problems for farmers in cultivating crops under conventional flood method of irrigation. Increased scarcity of water will create serious problems for small holders who mostly rely on vegetable cultivation for their livelihood. Therefore, promoting drip method of irrigation would curtail the distress of the red chilli cultivators.

Although red chilli crop is cultivated predominantly in many States, most farmers do not even know that red chilli cultivation under drip method of irrigation is economically viable even without availing of State subsidy. Poor awareness is still prevailing among the farmers on various advantages of drip method of irrigation in crop cultivation. Therefore, the benefits of cultivating red chilli under DMI need to be propagated through quality extension network on a continuous basis through various means. Although the study clearly shows that drip investment is economically viable for farmers cultivating red chilli, they generally opined that initial investment required for installing drip system for vegetable crops like red chilli is beyond their reach as they are mostly marginal and small farmers. Efforts should be made to provide drip system with low cost especially for vegetable crops cultivating smallholders by creating better research and development activities. Water scarcity has been increasing fast because of increased demand not only from agricultural sector but also from other sectors in India. Drip method of irrigation is proved to be an efficient water saving method and therefore, concerted effort should be made to expand its area where possible to escape from the threatening water scarcity which is aggravating day by day.

\section{Notes}

1. Extensive details on the current and future supply of and demand for water for the whole of India are provided in MoWR (1999) and CWC (2010).

2. Red chilli is a commonly cultivated vegetable crop in India which can also be cultivated under drip method of irrigation. But, not many detailed studies are available focusing on the economics of red chilli crop under drip method of irrigation. In fact, to our knowledge, not even a single study has been published on the economics of red chilli cultivation under drip method of irrigation in any of the leading journals in India. 
3. Though initiatives to popularise micro irrigation started as early as 1991 in the State, the progress has not been very appreciable mainly because of poor awareness about the usefulness of micro irrigation among the farmers. With the aim to improve the income of the farmers for two to three times within five years, the Government of Tamil Nadu in its budget of 2011-12 announced an ambitious programme for increasing the adoption of micro irrigation system, wherein the small and marginal farmers would get 100 per cent subsidy for putting up micro irrigation systems, while all other farmers would get 75 per cent subsidy (GoTN, 2012 \& 2014).

4. The cost used in this study is $A 2+F L$. As per the definition of Commission for Agricultural Costs and Prices (CACP), cost A2+FL includes all actual expenses in cash and kind incurred in production by the farmer plus rent paid for leased-in land as well as imputed value of family labour. The CACP has been using nine cost concepts for cost calculation, the definition of which can be seen from CACP (2005).

5. All the sample farmers in both DMI and FMI categories have used only electrically operated pumpsets for irrigating crops which require no or very less operating expenditure. Since electricity has been supplied free of cost to all farmers in Tamil Nadu over the last almost three decades, the cost of human labour used for managing water supply is only considered as irrigation cost in this study.

6. Reduction in labour use is one of the important advantages of drip method of irrigation that has not been highlighted by the existing studies. Many farmers have reported that they started adopting drip method of irrigation specifically to avoid labour scarcity in crops cultivation which accentuated due to the introduction of national rural employment guarantee scheme and fast growth in construction work in both rural and urban areas. Large amount of labour saving was observed in operations such as weeding, interculture, irrigation and land preparation. Since the major focus of the study was on economic viability of drip method of irrigation, the details of labour use in red chilli cultivation were not discussed in this paper.

7. As this profit is calculated only by deducting cost $A 2+F L$ from the gross value of production from red chilli crop, this should be appropriately called as farm business income. 


\section{References}

1. Amarasinghe, U.A., and V. Smakhtin (2014), "Global Water Demand Projections: Past, Present and Future," Research Report 156, International Water Management Institute, Colombo, Sri Lanka.

2. CACP (2005), "Report of the Commission for Agricultural Costs and Prices," Ministry of Agriculture, Government of India, New Delhi.

3. CWC (2010), "Water and Related Statistics," Central Water Commission, Ministry of Water Resources, Government of India, New Delhi.

4. Dhawan, B. D (2002), "Technological Change in Indian Irrigated Agriculture: A Study of Water Saving Methods," Commonwealth Publishers, New Delhi.

5. FICCI (2013), "Sustainable Agriculture: Water Management," Federation of Indian Chambers of Commerce and Industry, New Delhi.

6. Gittinger J, Price (1984), "Economic Analysis of Agricultural Projects," Second Edition, The Johns Hopkins University Press, London.

7. Gol (2004), "Report of Task Force on Micro Irrigation (Chairman: N. Chandrababu Naidu)," Ministry of Agriculture, Government of India, New Delhi, January.

8. Gol (2014), "Indian Agricultural Statistics," Directorate of Economics and Statistics, Ministry of Agriculture, New Delhi.

9. GoTN (2012), "Revised Budget Speech for 2011-12 by the Finance Minister of Tamil Nadu," Government of Tamil Nadu, Chennai.

10. GoTN (2014), “Vision Tamil Nadu 2023,” Government of Tamil Nadu, Chennai.

11. INCID (1994), "Drip Irrigation in India," Indian National Committee on Irrigation and Drainage, New Delhi.

12. MoWR (1999), "Report of the Working Group on Water Availability for Use," National Commission for Integrated Water Resources Development Plan, Ministry of Water Resources, Government of India, New Delhi.

13. MoWR (2006), "Report of Sub-Committee on More Crop and Income Per Drop of Water (Chairman: M.S. Swaminathan)," Ministry of Water Resources, Government of India, New Delhi.

Journal of Rural Development, Vol. 36, No. 3, July-September : 2017 
14. Narayanamoorthy, A (1996), "Evaluation of Drip Irrigation System in Maharashtra," Mimeograph Series No. 42, Agro-Economic Research Centre, Gokhale Institute of Politics and Economics, Pune, Maharashtra.

15. Narayanamoorthy, A (1997), "Economic Viability of Drip Irrigation: An Empirical Analysis from Maharashtra", Indian Journal of Agricultural Economics, Vol. 52, No.4, OctoberDecember, pp.728-739.

16. Narayanamoorthy, A (2003), "Averting Water Crisis by Drip Method of Irrigation: A Study of Two Water-Intensive Crops", Indian Journal of Agricultural Economics, Vol. 58, No. 3, JulySeptember, pp. 427-437.

17. Narayanamoorthy, A (2004), "Drip Irrigation in India: Can it Solve Water Scarcity?", Water Policy, Vol. 6, No.2, pp. 117-130.

18. Narayanamoorthy, A. (2004a), "Impact Assessment of Drip Irrigation in India: The Case of Sugarcane", Development Policy Review, Vol.22, No.4, pp. 443-462.

19. (2005), "Efficiency of Irrigation: A Case of Drip Irrigation," Occasional Paper: 45, Department of Economic Analysis and Research, National Bank for Agriculture and Rural Development, Mumbai, India.

20. (2005a), "Economics of Drip Irrigation in Sugarcane Cultivation: Case Study of a Farmer from Tamil Nadu", Indian Journal of Agricultural Economics, Vol. 60, No. 2, April-June, pp. 235-248.

21. (2009), "Water Saving Technologies as a Demand Management Option: Potentials, Problems and Prospects", in R.M. Saleth (Ed.) 'Promoting Irrigation Demand Management in India: Potentials, Problems and Prospects,' International Water Management Institute, Colombo, Sri Lanka.

22. Namara, R. E; Upadhyay, B; Nagar, R. K (2005), "Adoption and Impacts of Micro Irrigation Technologies: Empirical Results from Selected Localities of Maharashtra and Gujarat States of India," Research Report 93, International Water Management Institute Colombo, Sri Lanka.

23. NCPA (1990), "Status, Potential and Approach for Adoption of Drip and Sprinkler Irrigation Systems," National Committee on the Use of Plastics in Agriculture, Pune, India.

24. NHB (2014), "Indian Horticulture Data Base: 2014," National Horticulture Board (NHB), Ministry of Agriculture, Government of India, Gurgaon, India. 
25. Postal, S; Polak, P; Gonzales, F; Keller, J (2001), “Drip Irrigation for Small Farmers: A New Initiative to Alleviate Hunger and Poverty", Water International, Vol. 26, No. 1.

26. Shah, T (1993), "Groundwater Markets and Irrigation Development: Political Economy and Practical Policy," Oxford University Press, New Delhi.

27. Shah, T and Keller, J (2014), "Micro Irrigation Potential in the Developing Countries," in Goyal, M.R. (Ed.), 'Sustainable Micro Irrigation: Principles and Practices,' CRC Press, USA and Apple Academic Press, Oakville, Canada.

28. Shreshta, R.B. and Gopalakrishnan, C (1993), "Adoption and Diffusion of Drip Irrigation Technology: An Econometric Analysis", Economic Development and Cultural Change, Vol.41, No.2, January, pp.407-418.

29. Vanitha, S.M.; Chaurasia, S.N.S.; Singh, P.M and Naik, P.S. (2013), "Vegetable Statistics," Technical Bulletin No. 51, Indian Institute of Vegetable Research, Varanasi, India. 